\title{
Slow degradation of compostable plastic carrier bags in a stream and its riparian area
}

\author{
Maxime Artru and Antoine Lecerf* \\ EcoLab, Université de Toulouse, CNRS, INP, UPS, 118 route de Narbonne, Bât 4R1, Toulouse 31062, France
}

Received: 26 June 2019; Accepted: 30 August 2019

\begin{abstract}
There is no place on Earth where plastic debris could not be found. Impacts of plastics on aesthetics, biota and ecosystems are dependent on how long plastic items last, and what degradation products are released, in recipient environments. As bio-based plastics tend to replace petroleum-based plastics in everyday life, it is important to upgrade knowledge on the degradation of new polymers in natural environments. Single-use plastic carrier bags are nowadays made of bio-plastics certified as biodegradable and compostable. It is unclear, however, whether claims of biodegradability and compostability can be taken as evidence of rapid degradation of plastic bags outside recycling/composting facilities. This study sought to provide quantified information about the degradation of compostable plastic carrier bags in streams and riparian zones. We found that plastic samples enclosed in different types of mesh bags lost weight at extremely slow rates, albeit significant when submerged in a stream. 95\% of initial plastic mass remained after 77 days spent in water whereas alder leaf litter allowed to decompose under the same condition had completely disappeared before the end of the study. Determination of respiration rate and invertebrate abundance in plastic samples showed a greater decomposer activity in the stream than in the riparian environment. However, biotically-mediated degradation by decomposers was probably overridden by dissolution processes in mediating plastic mass loss. Our findings suggest that mismanaged plastic carrier bags could impact recipient ecosystems even when they are claimed as biodegradable or compostable.
\end{abstract}

Keywords: Biodegradable plastics / plastic degradation / aquatic ecosystems / litter decomposition / shredders

\section{Introduction}

Plastic pollution has raised as a major driver of global environmental change (Thompson et al., 2009a). Discharge of plastic debris into natural environments have been largely sustained by the ever-growing importance of single-use plastic products in everyday life (Plastics Europe, 2017). Plastic pollution causes aesthetic problems and harms wildlife through physical (ingestion and entanglement) and chemical (toxic effects of some chemical compounds) interactions (Thompson et al., 2009b). Part of the problem lies in the longterm persistence of widely produced plastic items as well as a tendency of plastics to disintegrate into micro- and nano-sized particles whose ecological impacts might exceed those of primary macroplastics (Barnes et al., 2009; Cole et al., 2011). Quantitative assessment of plastic degradation in natural environments is therefore an important prerequisite if we are to gain a robust understanding of how plastic pollution impacts biota and ecosystems.

\footnotetext{
*Corresponding author: antoine.lecerf@univ-tlse3.fr
}

Policies and efforts to reduce plastic pollution increasingly rely on banning conventional single-use plastics (Xanthos and Walker, 2017) while ensuring the design and commercialization of new biodegradable plastics (European Commission, 2000). Petroleum-based polymers are gradually replaced by biopolymers synthetized from raw biological materials as major constituents of biodegradable plastic carrier bags (Lambert and Wagner, 2017). As the presence of biopolymers does not necessarily imply that plastics are biodegradable, biodegradability is ascertained by the mean of standardized tests (Haider et al., 2019). Test conditions reflect biotic and abiotic conditions in recycling facilities where plastic wastes are expected to end up. Biodegradability claim is therefore unlikely to tell us whether mismanaged plastics are efficiently degraded in natural environments. However, latest biodegradability standards (e.g. AFNOR, 2015) and conformity marks (e.g. Vinçotte/TÜV AUSTRIA, 2013) developed for single-use plastic bags may provide further guarantees as to their shorter residence time in natural environments than banned conventional plastic bags.

The degradation and fate of single-use biodegradable plastics in natural environments are poorly understood 
(Harrison et al., 2018; Haider et al., 2019). Napper and Thompson (2019) found that biodegradable plastic carrier bags certified compostable disappeared completely from the marine environment within 3 months whereas they were still present after 27 months spent buried in soil. The authors also reported that exposition to sunlight in the open-air led to disintegration into fragments of all tested bags whether made of conventional or biodegradable plastics. Collectively, these results indicate that biodegradability assessed under natural conditions can greatly vary depending on habitat type, probably because of differences in the contribution of various biotic and abiotic agents to degradation. For instance, rapid aquatic and aerial degradation may arise due to the prevalence of dissolution processes and photodegradation, respectively. Plastic disappearance may also be faster where plastic-chewing invertebrates occur (Hodgson et al., 2018).

Fluvial transport of plastic wastes contributes substantially to plastic pollution in marine environments (Lebreton et al., 2017). Given the high capacity of lotic ecosystems to break down plant litter (e.g. leaf litter: Webster and Benfield, 1986; Graça and Canhoto, 2006) as well as to degrade refractory biopolymers (e.g. cellulose: Tiegs et al., 2019), it is conceivable that biodegradable plastic bags entering streams would undergo rapid degradation and thus would never reach oceans. Water flow is an effective agent of physical degradation of particulate organic matter through dissolution (=leaching) and abiotic fragmentation (Gessner et al., 1999). It also ensures rapid colonization of organic matter by stream decomposers and constant renewal of dissolved oxygen and nutrients they need to sustain high biological activities (Gessner et al., 2010). Decomposer activity also depends on physical and chemical characteristics of organic matter (Gessner and Chauvet, 1994; Graça and Canhoto, 2006). Plastic films and leaf litter are alike in some key physical characteristics, such as thinness and softness, suggesting that stream decomposers involved in leaf litter breakdown may also play a role in plastic biodegradation. This hypothesis has not yet been tested since, to our knowledge, no study to date has examined the degradation of biodegradable carrier bags in streams.

We set up a mesh bag experiment to assess degradation rate of biodegradable plastic carrier bags in a stream. The experiment was replicated in the riparian area next to the stream so as to proceed to an aquatic-terrestrial comparison. We aimed to determine how aqueous medium could influence plastic degradation in natural environments. As plastic bags tested in this study were certified as biodegradable in home compost heap (NF T 51-800 standards: AFNOR, 2015; Vinçotte/TÜV AUSTRIA OK compost HOME conformity mark), we hypothesized that water would not be a critical factor regulating plastic biodegradation. We also compared instream degradation and colonization by biota of biodegradable plastic film vs. leaf litter to determine whether degradation pathways differed between the artificial and natural substrates.

\section{Material and methods}

\subsection{Study site}

The study was carried out in a permanent first order stream (the Orival; $43^{\circ} 23^{\prime} \mathrm{N}, 2^{\circ} 6^{\prime} \mathrm{E}$ ) and its wooded riparian areas, in the Montagne Noire, southwestern France. The study area was situated in a broadleaf deciduous forest, upstream of main sources of human disturbance within the catchment. Previous studies conducted in this stream revealed the prevalence of natural oligotrophic condition (conductivity $=72.9 \mu \mathrm{S} \mathrm{cm}^{-1}:\left[\mathrm{P}_{-} \mathrm{PO}_{4}\right]=4.7 \mu \mathrm{g} \mathrm{L}^{-1}$ ) and the presence of elevated nitrate concentration $\left(\left[\mathrm{N}-\mathrm{NO}_{3}\right]=\right.$ $1.5 \mathrm{mg} \mathrm{L}^{-1}$ ) attributed to atmospheric nitrogen deposition (de Nadaï-Monoury et al., 2014). Occurrence of diverse macroinvertebrate community and rapid decomposition of leaf litter have also been noted (Dobson, 1994; de NadaïMonoury et al., 2014). Riparian vegetation was composed of beech (Fagus sylvatica L.) and oak (Quercus robur L.) trees, associated understory plants (Rubus) and typical riparian trees such as alder [Alnus glutinosa L (Gaertn)] and ash (Fraxinus excelsior L.). During the study period, water and air temperatures were recorded every 5 min using HOBO Pendant dataloggers (Onset Computer Corporation, Cape Cod, MA, U.S.A.).

\subsection{Biodegradable plastic bags}

We obtained a representative sample of $c a$. 30 biodegradable plastic bags from four French supermarket chains where such bags are supplied free-of-charge to consumers in fruit and vegetable sections. Though carrier bags sometimes looked different in terms of size, colors, extent and arrangement of printed areas, plastic film had broadly similar thickness $(10-12 \mu \mathrm{m})$ and mechanical performances. All carrier bags were made of at least $30 \%$ of bio-based material (PLA: Polylactic Acid) and they were certified as suitable for home composting (NF T 51-800 standards: AFNOR, 2015; Vinçotte/TÜV AUSTRIA OK compost HOME conformity mark).

\subsection{Mesh bag construction}

Plastic bags were cut into strips $(20 \times 15 \mathrm{~cm})$ to ensure optimal circulation of organisms and water or air within mesh bags. They were enclosed into coarse mesh bags made of plastic garden fence with a 5-mm mesh opening. The coarse mesh bags were submerged in the stream $(n=20)$ and deployed in the adjacent riparian area $(n=20)$. Plastic strips were also allowed to decompose in fine mesh bags made of $0.5 \mathrm{~mm}$ nylon net exposed in both environments (for each, $n=4$ ), to assess plastic mass loss owing solely to dissolution process and microbial activity. Additionally, alder leaf litter was enclosed into coarse mesh bags $(n=20)$ so as to compare decay rate and colonization pattern of plastic bags $v s$. plant litter in the stream. The leaves were previously collected at abscission and stored air-dried in a dry room until needed. All mesh bags contained $3 \mathrm{~g}( \pm 0.05 \mathrm{~g}$ with exact mass recorded) of air-dried plastic strips or alder leaf litter.

\subsection{Mesh bag installation}

Mesh bags filled with either plastic strips or alder leaf litter were deployed in the field on January 23rd, 2019. They were distributed across four blocks spaced $c a .7 \mathrm{~m}$ apart, in each environment (the stream and riparian area). Each block 
comprised five coarse mesh bags and one fine mesh bag containing plastic strips. In addition, blocks in the stream received each five coarse mesh bags containing alder leaf litter. Stream mesh bags were installed in areas of slow-moving water immediately downstream boulders and debris dams. They were tightened to heavy metal chains with both ends secured on an iron stick driven into the sediment. Riparian mesh bags were laid out flat on the topsoil surface underneath the soil litter layer. They were secured by means of wooden skewers driven into the soil through bag corners.

\subsection{Mesh bag recovery and processing}

One coarse mesh bag of each substrate (plastic strips and alder leaf litter) was sampled from the four blocks in each environment (the stream and riparian area) after 5, 14, 28, 49 and 77 days of exposure. Fine mesh bags were retrieved on the last sampling date. Mesh bags were enclosed individually in zip-lock bags and placed in a cool box during transport to the laboratory. Plastic strips or alder leaves recovered from each mesh bag incubated in stream were individually rinsed with tap water to remove biota and exogeneous matter (sand and detritus fragments). Plastic strips allowed to decompose in the riparian area were not washed to avoid potential leaching during sample processing. Instead, they were gently scrubbed with fingers to remove exogeneous debris (mainly litter fragments). The remaining material was oven-dried at $40{ }^{\circ} \mathrm{C}$ for five days and weighed to the nearest $0.01 \mathrm{~g}$.

\subsection{Invertebrate count and identification}

Macroinvertebrates from coarse mesh bags were counted and identified to meaningful taxonomic levels under a dissecting microscope (magnification up to $\times 60$ ). Stream macroinvertebrates were previously collected on a $0.5-\mathrm{mm}$ sieve whereas terrestrial macroinvertebrates were picked directly from plastic strips using forceps.

\subsection{Microbial respiration}

We assessed microbial respiration of substrates allowed to degrade in stream using a 6-channel optical dissolved oxygen monitoring system (SDR SensorDish ${ }^{\circledR}$ reader, Presens $\mathrm{GmbH}$ ). Five $1.7 \mathrm{~cm}$ diameter discs were cut out from each sample of plastic strips or alder leaf litter and then placed in a $15 \mathrm{~mL}$ well filled with filtered $(0.45 \mu \mathrm{m}$ pore size) stream water. One well out of the six was used as a control and contained only water. Oxygen concentration was measured in the six wells every 15 second for an hour. The time series were truncated at both ends to analyze the linear portion only. Oxygen consumption rate was estimated as the slope of oxygen trend corrected for rate of oxygen change in the control well. Respiration rate was expressed by unit of litter mass and converted into carbon flux assuming a respiratory coefficient of 1 . Microbial respiration of plastic strips allowed to decompose in the riparian area was assessed by the mean of a portable infra-red $\mathrm{CO}_{2}$ gas analyzer (EGM-5, PP Systems) fitted with a soil respiration chamber (SRC-2, PP Systems). Once cleaned, plastic strips
Table 1. Extent of the degradation of biodegradable plastic strips enclosed in coarse or fine mesh litter-bags and allowed to decompose for 77 days in a stream or in the adjacent riparian zone. $R=$ mean proportion of litter mass remaining relative to initial mass. $\mathrm{SE}=$ standard error. Superscript letters depict statistically different groups of samples (see Results).

\begin{tabular}{lll}
\hline Condition & $R$ & SE \\
\hline Stream - coarse mesh & $0.95^{\mathrm{a}}$ & 0.01 \\
Stream - fine mesh & $0.96^{\mathrm{a}}$ & 0.00 \\
Riparian - coarse mesh & $1.02^{\mathrm{b}}$ & 0.01 \\
Riparian - fine mesh & $0.97^{\mathrm{a}}$ & 0.01 \\
\hline
\end{tabular}

were enclosed in the respiration chamber sealed with a plastic film (Parafilm M).

All respiration measurements were done in a thermostated room at $10^{\circ} \mathrm{C}$ in the dark, where samples were allowed to rest for one hour prior measurements. Plastic strips from riparian area were sprayed with distilled water as needed to ensure minimal moisture level of the samples.

\subsection{Statistical analyses}

Kruskal-Wallis test was used to compare conditions under which plastic strips were allowed to degrade in the field (coarse $v s$. fine mesh bags exposed in stream $v s$. riparian area).

Linear regression was performed to dissect trajectories of plastic strip degradation in each environment. The first-order decay model was fitted to the data using non-linear regression in order to estimate decay rate $\left(k\right.$ in day $\left.{ }^{-1}\right)$ of biodegradable plastic bags and alder leaf litter.

To compare respiration rate of plastic film vs. leaf litter incubated in stream, we calculated cumulative carbon releases until one substrate type had disappeared completely from mesh bags (i.e. until 49 days as alder leaf litter were not found afterward). Estimates for each environment was obtained based on calculation of area under the curve with linear interpolation between data points.

\section{Results}

Temperatures measured throughout the course of the field study displayed a greater variability in the riparian area $\left(-1.3\right.$ to $\left.22.7^{\circ} \mathrm{C}\right)$ than in the stream $\left(3.6-11.1^{\circ} \mathrm{C}\right)$. Mean values were, in contrast, fairly close to each other (air: $6.7^{\circ} \mathrm{C}$; water: 7.2 $\left.{ }^{\circ} \mathrm{C}\right)$.

After 77 days spent in natural environments, samples of biodegradable plastic bags had lost at most $5 \%$ of their initial mass (Tab. 1). Rate of plastic degradation was not uniform across types of mesh bags and substrates (Kruskal-Wallis test: $\left.\chi^{3}=8.1, P=0.0428\right)$. Plastic degradation did not occur in coarse mesh bags in riparian area whereas mass loss was detected for plastic samples tested in other conditions (Tab. 1). Conditions where plastic degradation occurred (i.e. mass remaining $R<1$ ) did not differ from each other (KruskalWallis test: $\left.\chi^{2}=0.5, P=0.77\right)$. This shows that mesh size did 


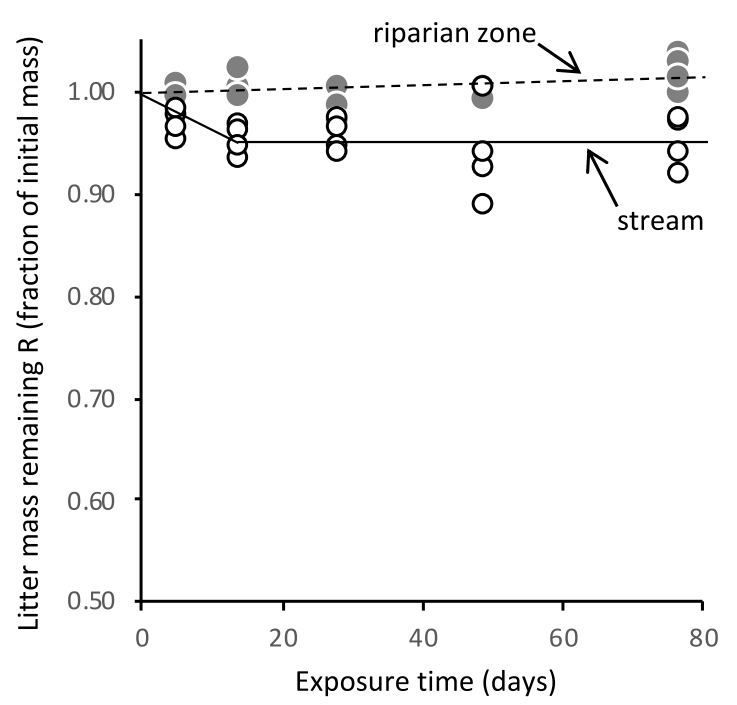

Fig. 1. Plastic litter mass remaining in coarse mesh bags incubated in a stream (open dots) and its riparian area (solid dots). The solid and dashed lines represent corresponding least-square estimated linear trends for the stream and riparian area, respectively. Note that the $y$-axis starts from 0.5 .

not affect in-stream plastic degradation and degradation rate in fine mesh bags were comparable in the aquatic and terrestrial habitats.

Plastic mass loss was undetectable in coarse mesh bags set in riparian area since mass remaining across all sampling dates did not deviate significantly from one (one sample $t$-test: $t_{19}=-0.5, P=0.62 ;$ Fig. 1$)$. The decomposition trajectory displayed a slight increase through time (linear regression: $r^{2}=0.22$, slope $=+0.03 \%$ day $^{-1}, t_{18}=2.3, P=0.0346$ ). In contrast, plastic mass remaining in coarse mesh bags incubated in stream was always below initial mass $(R<1)$ from the first sampling date (one sample $t$-test: $t_{19}=-8.6, P<0.0001$; Fig. 1). Plastic mass loss occurred exclusively during the first two weeks of submersion $\left(-5 \%\right.$ : slope $=-0.36 \%$ day $\left.^{-1}\right)$, then a flat trajectory was recorded (linear trend: slope $<-0.0001 \%$ day $\left.^{-1}, t_{14}=-0.2, P=0.81\right)$. Exponential litter decay constant was estimated to be 0.0010 day $^{-1}$ (non-linear regression: $\left.t_{19}=5.2, P<0.0001\right)$.

Respiration rate of biodegradable plastic samples was twoorder of magnitude greater in the stream than in riparian zone (Fig. 2). In stream, respiration rate showed a rapid initial increase from 0 to 5 days and peaked at 47 days. In riparian area, respiration rate tended to increase slowly with time (Pearson correlation: $r=0.43, P=0.0570$ ).

Macroinvertebrates were found in coarse mesh bags filled with plastic strips incubated in both stream and riparian environments (Tab. 2). They were 3.5 times more abundant in stream samples than in riparian samples. Typical litterconsuming taxa were present in stream samples (i.e. shredders: Nemouridea, Limnephilidae, Gammaridae, Sericostomatidae) whereas functionally analogous taxa (e.g. Isopoda, Diplopoda) were not found in riparian samples (Tab. 2).

There were fundamental differences between decaying plastic strips and leaf litter incubated in stream (Tab. 3). Plastic degradation was 28 times slower than the decomposition of

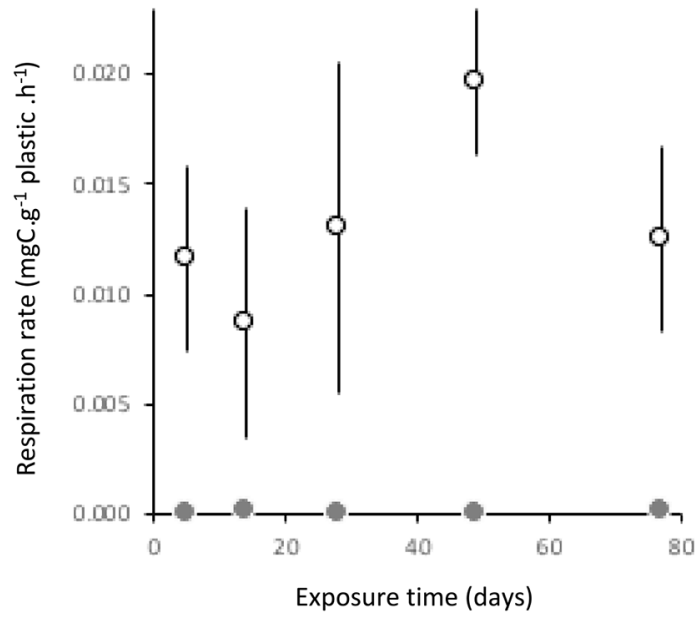

Fig. 2. Respiration rate of plastic strips allowed to decompose in stream (open dots) and riparian area (solid dots) in coarse mesh bags sampled on five occasions. Points and error bars represent means and standard errors, respectively.

Table 2. Macroinvertebrate taxa recovered from plastic strips in coarse mesh bags incubated in a stream and its riparian area. Abundance are cumulated values over five sampling dates.

\begin{tabular}{ll}
\hline Habitat/taxon & Ind. number
\end{tabular}

\section{Stream}

Chironomidae (F) 12

Nemouridea $(\mathrm{sF}) \quad 12$

Simuliidae (F) 11

Limnephilidae (F) 10

Oligochaetea $(\mathrm{sC}) \quad 8$

Tricladida $(\mathrm{O}) \quad 7$

Gammaridae (F) 5

Hydropsychidae (F) 3

Athericidae $(\mathrm{F}) \quad 2$

Leptophlebiidae (F) 2

Sericostomatidae (F) 1

Ecnomidae (F)

Zygoptera (sO)

\section{Riparian area}

Acarina (sC)

Collembola $(\mathrm{sC})$

Arachnida (C)

Oligochaetea $(\mathrm{sC})$

Gasteropoda (C)

Lepidoptera $(\mathrm{O})$

alder leaf litter. Mass loss after 5 days of immersion was 7.5 greater for alder leaf litter than plastic strips. Cumulative respiration until complete disappearance of alder leaf litter from mesh bags (i.e. 49 days) was 8.5 greater than that of plastic strips. Macroinvertebrates were fewer in coarse mesh bags filled with plastic strips than those with alder leaf litter. 
Table 3. Comparison of functional and structural metrics associated with two types of decaying particulate organic matter in coarse mesh litter bags in stream. $k=$ exponential decay rate.

\begin{tabular}{lll}
\hline & Plastic strips & Alder leaf litter \\
\hline$k\left(\right.$ day $\left.^{-1}\right)$ & 0.0010 & 0.0278 \\
$\begin{array}{l}\text { Leaching (\%mass loss after } \\
5 \text { days in stream) }\end{array}$ & 3.2 & 24 \\
$\begin{array}{l}\text { Cumulative respiration until } \\
49 \text { days (mgC) }\end{array}$ & 15.0 & 127.0 \\
$\begin{array}{l}\text { Total abundance of } \\
\text { macroinvertebrates }\end{array}$ & 75 & 128 \\
Shredders (\%abundance) & $28(37 \%)$ & $59(46 \%)$ \\
\hline
\end{tabular}

The contribution of shredders to total invertebrate abundance reached almost $50 \%$ in alder leaf bags and was lower in plastic strip bags (Tab. 3).

\section{Discussion}

In the present study, biodegradable plastic carrier bags tended to lose weight faster when submerged in stream than when laid on stream bank soil. The subsequent hypothesis that plastic biodegradation is enhanced in aquatic environment is consistent with previous observations made in both marine and terrestrial environments (Napper et al., 2019). These authors reported that it takes less than 9 months for plastic samples to achieve full degradation in the marine environment. Although our experiment lasted less than 3 months, the very small (5\% of initial mass) amount of plastic mass lost within this timeframe suggests that aquatic biodegradation was slower here than in the previous study. The decay rate calculated here $\left(0.0010\right.$ day $\left.^{-1}\right)$ indicates that two years of exposure in the stream would be required to reach the half-life of biodegradable plastic carrier bags. However, extrapolating the starting portion of degradation trajectory is fraught with uncertainties linked to seasonal change in environmental conditions that could influence later decomposition stage (e.g. increasing water temperature and shift in decomposer community structure from Spring to Summer).

Biodegradable plastic samples incubated in the stream reached their final mass after only two weeks of immersion. In such a short timeframe, abiotic processes are expected to make the largest contribution to organic matter degradation (Gessner et al., 1999). In contrast, physical abrasion was likely unimportant since plastic degradation did not differ whether submerged plastic samples were exposed in coarse or fine mesh bags. Lack of clear difference in plastic mass remaining in fine mesh bags between the stream and riparian area suggests that water may not be that important in mediating plastic degradation. However, as water may be efficiently trapped and retained inside fine mesh bags set in terrestrial habitats, thereby enhancing artificially water-mediated degradation processes, results of plastic decomposition in coarse mesh bags should rather be used to make meaningful comparison of aquatic $v s$. terrestrial degradation. Thus, imperceptible mass change in soil indicates that permanent contact with water may be instrumental for initial plastic degradation in natural environments. Slow plastic degradation in riparian area may therefore reflect the dependence of dissolution process to rainfall events. In addition, entry of exogeneous particulate matter into coarse mesh bags, that added to the weight of plastic strips in riparian area, may explain the apparent small increase of plastic mass found here (Fig. 1).

Aqueous conditions promoted microbial colonization of plastic strips since microbial respiration increased more rapidly, and to a greater extent, in stream than in riparian soil. This is because liquid medium ensures high dispersal rate and stable metabolic activity of microorganisms compared with soils where moisture is a key factor limiting heterotrophic activity (Gessner et al., 2010). However, stream microbial community did not prove effective at degrading submerged biodegradable plastic bags as we did not record significant plastic mass loss after 14 days of incubation. Microbial respiration was much lower on plastic film than on leaf litter, hinting at large differences in microbial biomass and/or community structure between the substrates. Aquatic hyphomycete fungi dominate microbial communities on leaf litter submerged in streams (e.g. Hieber and Gessner, 2002; Majdi et al., 2015). There are some reasons to believe that this key decomposer group may be less dominant in microbial community developing on plastic film. For instance, the smooth and homogeneous surface of plastic film may prevent effective trapping of fungal conidia through which initial fungal colonization occurs (Dang et al., 2007). In addition, fungal colonization may be restricted to the surface layer of plastic film whose toughness and thinness may prevent deep penetration of fungal hyphae within the plastic matrix.

Stream invertebrates were found in abundance in coarse mesh bags filled with biodegradable plastic strips. As plastic mass loss was similar in coarse and fine mesh bags, it is reasonable to assume that invertebrates used plastic strips as an habitat rather than food (Richardson, 1992). Dangles et al. (2001) used non-degradable plastic strips cut into shape similar to that of leaf litter to compare invertebrate colonization with that of natural leaf litter. They found that the diversity and abundance of invertebrates tended to be higher in a refractory leaf litter (beech) than in the synthetic substrate. Moreover, they also reported that invertebrate colonization of plastic strips was enhanced by the presence of exogeneous particulate organic matter trapped into mesh bags.

We observed that Isopods were quite abundant in the litter layer of the riparian soil; however, no such large detritivorous invertebrates were found in plastic strips. This provides further indications that invertebrates did not play a role in the degradation of biodegradable plastic bags. Ability of invertebrates to chew and fragment plastic films has been documented for marine amphipods (Hodgson et al., 2018). To examine whether stream detritivores, too, are able to consume plastic films, we conducted a short-term laboratory feeding experiment (data not shown). Discs of compostable plastic films colonized by a biofilm were offered to individuals of the amphipod Gammarus sp. (Gammaridae) or limnephilid (Limnephilidae) caddisfly larvae. Less than $50 \%$ of gammarid individuals were found to shred on edges of plastic discs and to release small plastic fragments $(<1 \mathrm{~mm})$ in microcosms. 
No such observation was made in microcosms with limnephilid individuals, indicating that biotic fragmentation of biodegradable plastic film may not be a primary degradation pathways in natural environments.

Focal plastic carrier bags achieved some of the highest biodegradability standards (90\% mass loss achieved within a year in a home compost heap: Vinçotte/TÜV AUSTRIA, 2013) among widely distributed products. Therefore, we did not expect to find such slow plastic mass loss in natural environments. Our finding can be partly explained by temperature difference between standard conditions under which biodegradation is tested (typically $20-30{ }^{\circ} \mathrm{C}$; Vinçotte/TÜV AUSTRIA, 2013) and environmental conditions encountered during this experiment ( $c a .7{ }^{\circ} \mathrm{C}$ on average; $<23^{\circ} \mathrm{C}$ in soil). It is worth noting, however, that cool water temperature did not preclude alder leaf litter to have completely disappeared from coarse mesh bags set in stream before the end of the experiment. Fast leaf litter degradation in streams is largely sustained by decomposer activity (Hieber and Gessner, 2002). It is unclear why stream decomposers had an imperceptible effect on plastic biodegradation here. Whether decomposers are unable to degrade biopolymers and use them as energy source or toxic effects of other plastic compounds (e.g. additives) hamper their activity have to be determined (Harrison et al., 2018).

Replacement of petroleum-based polymers by biopolymers in single-use plastic items has been assumed to reduce widespread ecological and aesthetical impacts of plastic littering on natural environments. This strategy may, in fact, exacerbate littering behavior owing to the misconception that products certified "biodegradable" are safe for biota and ecosystems. Here we show that biodegradable plastic carrier bags are quite resistant against biotic and abiotic agents underpinning degradation in natural environments. Long residence time of biodegradable plastic bags indicate that some of their effects on wildlife and ecosystems may be the same as those documented for conventional plastics (e.g. Barnes et al., 2009; Cole et al., 2011). In addition, biodegradable plastics may impact ecosystems through the release of specific degradation products, such as leachable compounds, whose fate and effects in ecosystems have yet to be investigated. Such knowledge will help guide industrial efforts to improve plastic biodegradability and reduce plastic footprint on natural environments.

Acknowledgements. We thank F. Julien and T. Rota for technical support in the laboratory. Two anonymous reviewers provided constructive comments that helped us improve the manuscript.

\section{References}

AFNOR. 2015. Plastics - Specifications for plastics suitable for home composting. NF T51-800.

Barnes DKA, Galgani F, Thompson RC, Barlaz M. 2009. Accumulation and fragmentation of plastic debris in global environments. Phil Trans R Soc B 364: 1985-1998.

Cole M, Lindeque P, Halsband C, Galloway TS. 2011. Microplastics as contaminants in the marine environment: a review. Mar Pollut Bull 62: 2588-2597.
Dang CK, Gessner MO, Chauvet E. 2007. Influence of conidial traits and leaf structure on attachment success of aquatic hyphomycetes on leaf litter. Mycologia 99: 24-32.

Dangles O, Guérold F, Usseglio-Polatera P. 2001. Role of transported particulate organic matter in the macroinvertebrate colonization of litter bags in streams. Freshw Biol 46: 575-586.

de Nadaï-Monoury E, Gilbert F, Lecerf A. 2014. Forest canopy cover determines invertebrate diversity and ecosystem process rates in depositional zones of headwater streams. Freshw Biol 59: $1532-1545$.

Dobson M. 1994. Microhabitat as a determinant of diversity: stream invertebrates colonizing leaf packs. Freshw Biol 32: $565-572$.

European Commission. 2000. EN 13432:2000. Requirement for packaging recoverable through composting and biodegradation Test scheme and evaluation criteria for the final acceptance of packaging.

Gessner MO, Chauvet E. 1994. Importance of stream microfungi in controlling breakdown rates of leaf litter. Ecology 75: 1807-1817.

Gessner MO, Chauvet E, Dobson M. 1999. A perspective on leaf litter breakdown in streams. Oikos 85: 377-384.

Gessner MO, Swan CM, Dang CK, McKie BG, Bardgett RD, Wall DH, Hättenschwiler S. 2010. Diversity meets decomposition. Trends Ecol Evol 25: 372-380.

Graça MAS, Canhoto C. 2006. Leaf litter processing in low order streams. Limnetica 25: 1-10.

Haider TP, Völker C, Kramm J, Landfester K, Wurn FR, 2019. Plastics of the future? The impact of biodegradable polymers on the environment and on society. Angew Chem Int Ed 58: 50-62.

Harrison JP, Boardman C, O'Callaghan K, Delort A-M., Song J. 2018. Biodegradability standards for carrier bags and plastic films in aquatic environments: a critical review. $R$ Soc Open Sci 5: 171792.

Hieber M, Gessner MO. 2002. Contribution of stream detritivores, fungi, and bacteria to leaf breakdown based on biomass estimates. Ecology 83: 1026-1038.

Hodgson DJ, Bréchon AL, Thompson RC, 2018. Ingestion and fragmentation of plastic carrier bags by amphipod Orchestia gammarellus: effects of plastic type and fouling load. Mar Pollut Bull 127: 154-159.

Lambert S, Wagner M. 2017. Environmental performance of biobased and biodegradable plastics. The road ahead. Chem Soc Rev 46: 6855-6871.

Lebreton LCM, van der Zwet J, Damsteeg J-W, Slat B, Andrady A, Reisser J. 2017. River plastic emissions to the world's oceans. Nat Commun 8: 15611.

Majdi N, Traunspurger W, Richardson JS, Lecerf A. 2015. Small stonefly predators affect microbenthic and meiobenthic communities in stream leaf packs. Freshw Biol 60: 1930-1943.

Napper I, Thompson RC. 2019. Environmental deterioration of biodegradable, oxo-biodegradable, compostable, and conventional plastic carrier bags in the sea, soil, and open-air over a 3-year period. Environ Sci Technol 53: 4775-4783.

Plastics Europe. 2017. Plastics-the facts 2017: an analysis of European plastics production, demand and waste data. http://www. plasticseurope.org (accessed on 15/06/2019)

Richardson JS. 1992. Food, microhabitat, or both? Macroinvertebrate use of leaf accumulations in a montane stream. Freshw Biol 27: $169-176$.

Thompson RC, Swan SH, Moore CJ, vom Saal FS. 2009a. Our Plastic age. Phil Trans $R$ Soc B 364: 1973-1976.

Thompson RC, Swan SH, Moore CJ, vom Saal FS. 2009b. Plastics, the environment and human health: current consensus and future trends. Phil Trans $R$ Soc B 364: 2153-2166. 
Tiegs SD et al. 2019. Global patterns and drivers of ecosystem functioning in rivers and riparian zones. Sci Adv 5: eaav0486.

Vinçotte/TÜV AUSTRIA. 2013. Certification scheme OK compost HOME. http://www.tuv-at.be/fileadmin/user_upload/docs/down load-documents/english/Program_OK_02e_d_OK_compos t_HOME.pdf (accessed 24/06/2019)
Webster JR, Benfield EF. 1986. Vascular plant breakdown in freshwater ecosystems. Ann Rev Ecol Syst 17: 567-594.

Xanthos D, Walker TR. 2017. International policies to reduce plastic marine pollution from single-use plastics (plastic bags and microbeads): a review. Mar Pollut Bull 118: 17-26.

Cite this article as: Artru M, Lecerf A. 2019. Slow degradation of compostable plastic carrier bags in a stream and its riparian area. Ann. Limnol. - Int. J. Lim. 55: 18 